\title{
High Density Polyethylene (HDP) Pipe as a Lining Material in Hilly Regions of Nepal
}

\section{Krishna Prasad Rijal}

Abstract: Canal lining is a major part of construction in irrigation projects. Canal lining determines the cost of project to a great extent but also the discharge delivery efficiency of the irrigation system. Though earthen canal sections are least expensive, simple to maintain and environmentally friendly, they have high seepage rates and demand frequent repair. In the light of need for resource conservation and the general unavailability of labour for maintenance work, a canal lining, though more expensive, may be justifiable in the long run. Technological advances in the construction have made available lighter and more affordable materials that enhance many parts of the irrigation process.

It is the private sector that should lead the development of these technologies as they relate to the construction business. We can look to foreign markets to see how canal lining technologies have improved the use of this tool in various environments and soils. In the Nepali context, we use traditional lining techniques like stone or reinforced concrete, which are effective in the plains, but less so in the hills and remote. In this paper, I review some alternatives to traditional canal linings, and examine the virtues of high density polyethylene (HDP) pipe for possible use in irrigation schemes.

Keywords: Canal Lining, HDP pipe, RCC, Hills, Nepal

\section{Introduction}

Trigating land with earthen canals is the age1 old tradition in Nepal. Farmers would dig canals relatively more steeply than the canals of today. They employed local materials and labor for construction. There are many advantages to this traditional method: it is environmentally friendly and relatively inexpensive and easy to repair. However, these canals are limited in effectiveness by their length of construction, few cross drainage structures, and a small canal area. But today, technological advances in construction materials and methods have enabled irrigation systems to deliver more water to further reaches of arable land.

For irrigation canals, efficiency of discharge delivery is the most important factor. Earthen canals, in this regard, fare poorly as they have high seepage loss of water. For this reason, other materials such as Reinforced Concrete Cement (RCC) has become the most commonly used material for canals in Nepal. Other materials frequently used include masonry, slate and pipe linings. The material selected is considered along with other factors such as topography, material availability, operational flexibility and discharge efficiency. In the hills, canal linings are more difficult to use due to challenges in transporting the materials, constructing the canal with these materials and maintaining their quality. Inappropriately designed linings may have less efficiency and come with a high cost. Therefore, a critical assessment of canal linings is necessary at this point in time.

\section{High Density Polyethylene (HDP) Versus Other Types of Canal Linings}

\section{Hydraulic Efficiency}

The most efficient form for hydraulic flow is semicircular in shape. Circular HDP pipes can be ideal for this purpose. Alternative sections can be either trapezoidal or rectangular: this works best in flat areas. However, in rocky areas and unstable zones, it is difficult to maintain a trapezoidal shape as it needs greater width which can be difficult to provide on

steep terrain. On the other hand, rectangular sections occupy less width in canal, but earthen canals cannot be made to hold this shape. For rectangular canals, stone masonry or RCC linings are necessary, and these are expensive.

Lowering flow resistance is another primary concern for canal materials. Manning's roughness algorithm calculates the smoothness of the walls in relation to water flow. HDP pipe has a Manning's roughness factor of 0.008 compared to RCC (0.015), stone masonry (0.020), and earthen canals (0.30). Additionally, the plastic in HDP maintains its Manning value over time, unlike other materials. Figure 1 is a simplified graph generally used in HDP pipe design for irrigation purpose developed by the author based on Hazen-William's equation for pipe flow.

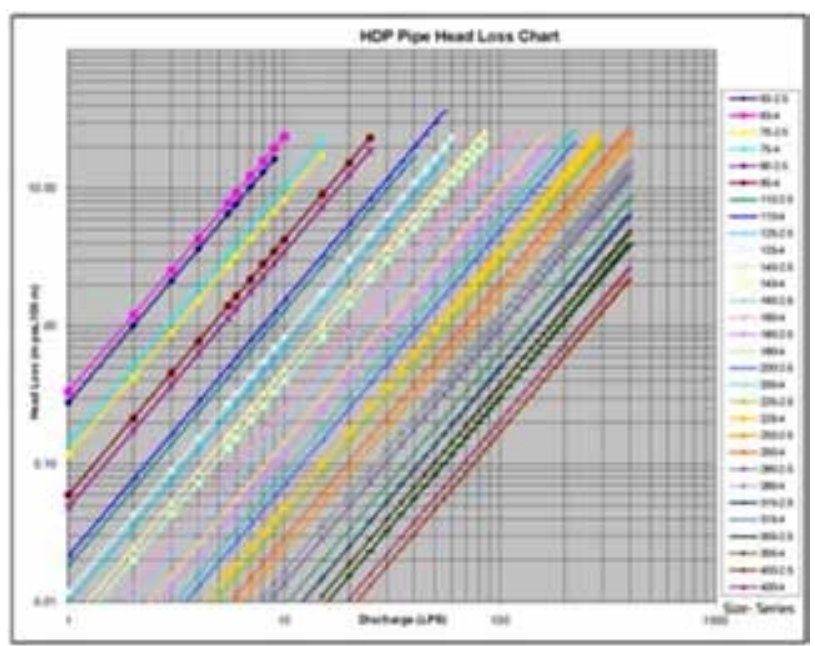

Figure 1: HDP Pipe design chart for irrigation

\section{Cost Effectiveness}

HDP is more cost effective for two reasons: 1) smaller pieces are required to achieve the same discharge rates compared with other materials; and 2) the slimness and light weight of HDP make it suitable for transport into remote and hilly areas of Nepal. In the past, a significant portion of construction costs for 
irrigation was due to transportation costs. Cement, obviously, is bulky and heavy for transport. Plus, cement and other materials require employing more labor for transport and construction, thus pushing up the cost. HDP pipe can also be physically flexible and does not require the evacuation of large rocks, which is also expensive. Instead, HDP pipe can be left unburied in these areas and held in place with simple anchoring. When we compare cost per meter of HDP and cement canals from various irrigation projects in Dolakha district, we find cement (RCC) is approximately $45 \%$ higher (Table 1 ).

\begin{tabular}{|c|c|c|c|}
\hline \multirow{2}{*}{$\begin{array}{l}\text { S. } \\
\text { No. }\end{array}$} & \multirow[t]{2}{*}{ Project Name } & \multicolumn{2}{|c|}{$\begin{array}{c}\text { Per meter Rate of } \\
\text { Lining (NRs) }\end{array}$} \\
\hline & & RCC & HDP Pipe \\
\hline 1 & Pulakhola Irrigation Project (IP) & 4733 & 3204 \\
\hline 2 & Budhathoki Kulo IP & 4123 & 6696 \\
\hline 3 & Rajkulo IP & 2726 & 4002 \\
\hline 4 & Sailungfedi IP & 3885 & 2720 \\
\hline 5 & Phadke Khola IP & 4491 & 1394 \\
\hline 6 & Chyanseghari IP & 4495 & 682 \\
\hline 7 & Kabre IP & & 2252 \\
\hline 8 & Jhorkhola IP & & 1484 \\
\hline & Average rate per meter lining & 4075.5 & 2804.25 \\
\hline
\end{tabular}

Table1: Comparison of cost of lining per meter length of some irrigation projects in Dolakha District

(Data source: Irrigation Development Division, Dolakha)

\section{Suitability in Flood Plains, Fragile and Steep Lands}

Constructing irrigation canals in unstable and sliding zones is a major challenge in the hilly areas of Nepal. HDP offers a nice alternative. Because it is light, the slope will not bear further weight due to the structure, thus minimizing erosion and the possibility of small landslides. Cement and heavier materials can trigger further instability in steep areas. HDP is preferable in such because it can shift more easily with the land; seismic movements will not cause it to crack or break, unlike concrete. Even if HDP pipe should rupture, it can be easily repaired and/or replaced (photo 1).

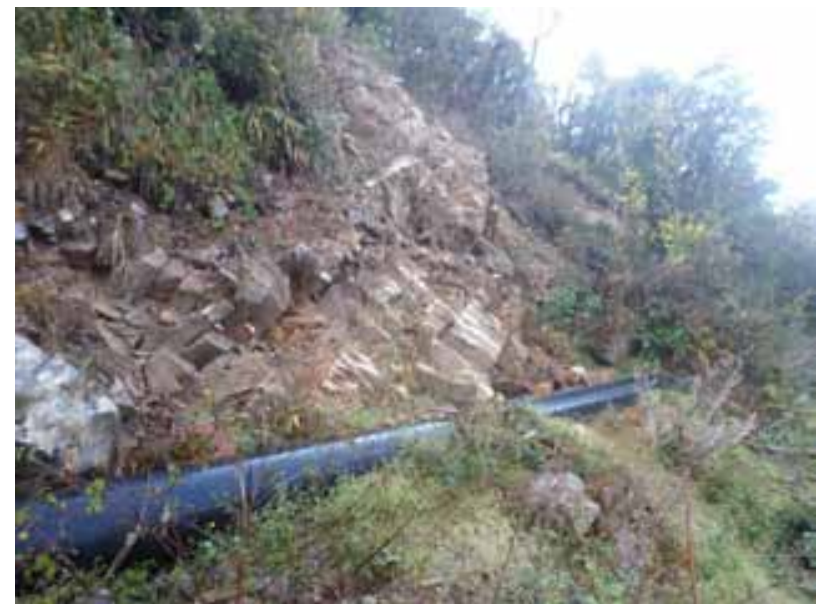

Photo1: HDP pipe functioning well in Earthquake triggered landslide

\section{Quality of Works and Durability}

Durability and quality control are major challenges in hilly areas that are steep and fragile. The quality of construction relies on the availability of skilled labor, and access to quality material and tools. Cement, for obvious reasons, requires more labor and more equipment for installation: bar binders, form workers, and masons. The sand required for cement mixing also presents another demand on the farmers as sand and aggregate are not always readily available (Photo 3). Photo 2 illustrates the aggregate quality in most hill sites. Let us also remember that cement mixing and curing is temperature and moisture sensitive. None of these factors affects the quality and efficiency of HDP. Installation of HDP requires only a trained plumber and a few laborers to complete the work quickly and effectively.

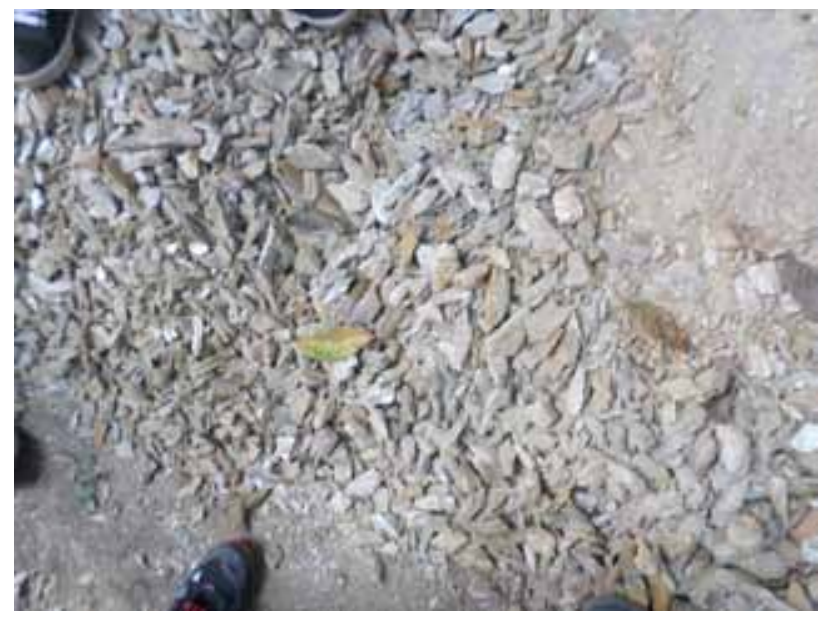

Photo 2: Aggregate quality in hills (flaky and elongated)

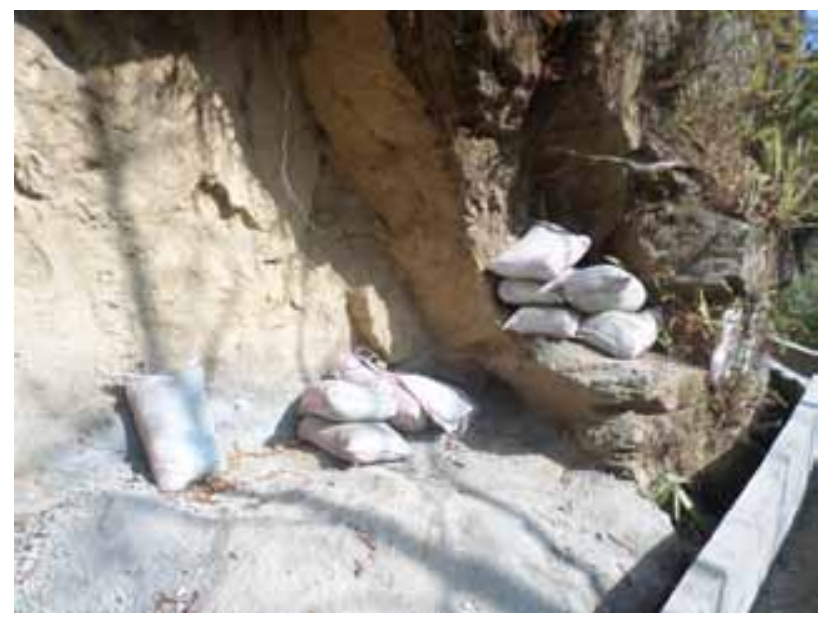

Photo 3: Cement storage at site: example of improper storage

\section{Environmentally Friendly}

HDP pipe material is environmentally friendly and easy to use. Unlike to cement materials, it is chemically less sensitive. It does not require a maturity period to gain strength. Because of its lightness, HDP doesn't trigger slides in unstable slope as compared to other heavy masonry structures. A part from these differences, HDP pipe presents less of an obstacle to local wildlife that may travel in the area. 


\section{Less Time for Construction}

HDP pipe lining takes less time to install than cement systems (Figure 2). For one, you can install various stretches of lining simultaneously rather than one section at a time, whereas RCC requires a very ordered sequential process of long duration, which increases your need for dependable labor.

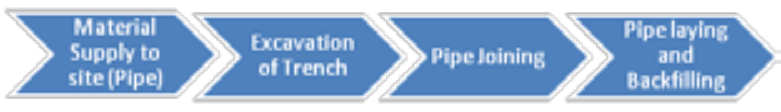

Work steps of HDP pipe Lining

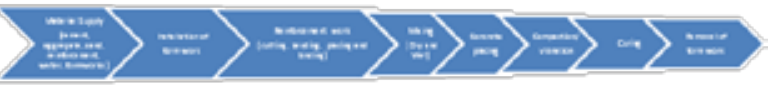

Work steps of RCC Lining

Figure 2: The work Steps for HDP and RCC linings Compared

\section{Earthquake Resilience}

As Nepal is seismically active, these effects must be considered in design. HDP has an obvious advantage due to its light weight and overall superior flexibility without rupture. In fact, HDP was commonly used after the April 2015 earthquake to restore productivity to arable lands as quickly as possible. For instance, people in Dolakha district have been demanding HDP

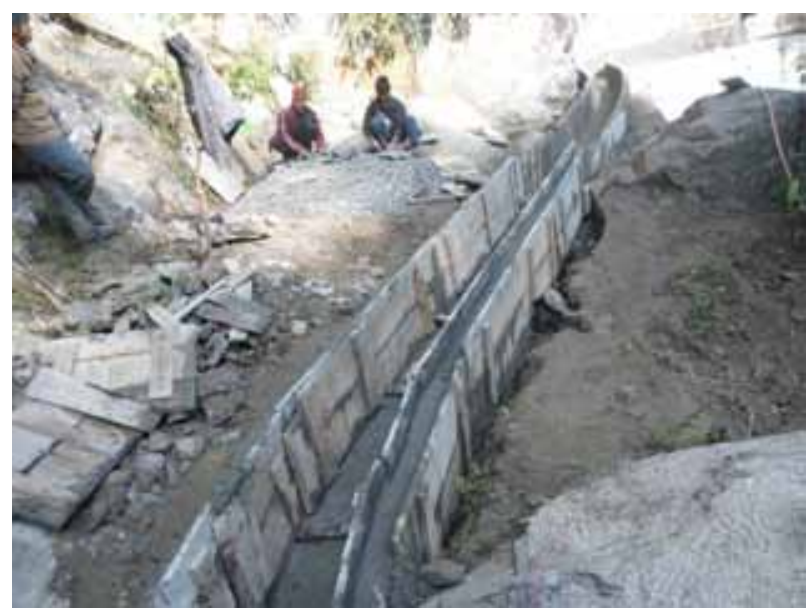

Photo 4: Cement concrete lining work includes a number of work steps

for their irrigation systems since that time.

\section{Avoidance of Heavy and Costly Structures}

HDP pipe is not only suitable for water conveyance but it can also replace heavy and costly structures used in irrigation system. Foot bridge and village road bridge are the examples. With the selection of right class of pipe and adequate cushion provided, HDP pipe can replace these structures. Similarly, heavy aqueducts can be avoided by introducing simple super passage by slightly shifting the alignment towards the downstream of the drain at the point of crossing. Similarly, multi-span RCC aqueducts with heavy piers, beams, and trough can be simply replaced by suspended cable crossing. This reduces the cost of drainage crossing structure drastically, as well as the time of construction. Durability of such structure is high because such work is less dependent to the flow condition of drain, drain bed morphology and hydrological uncertainties. Figure 5 shows the comparison of HDP and masonry drops

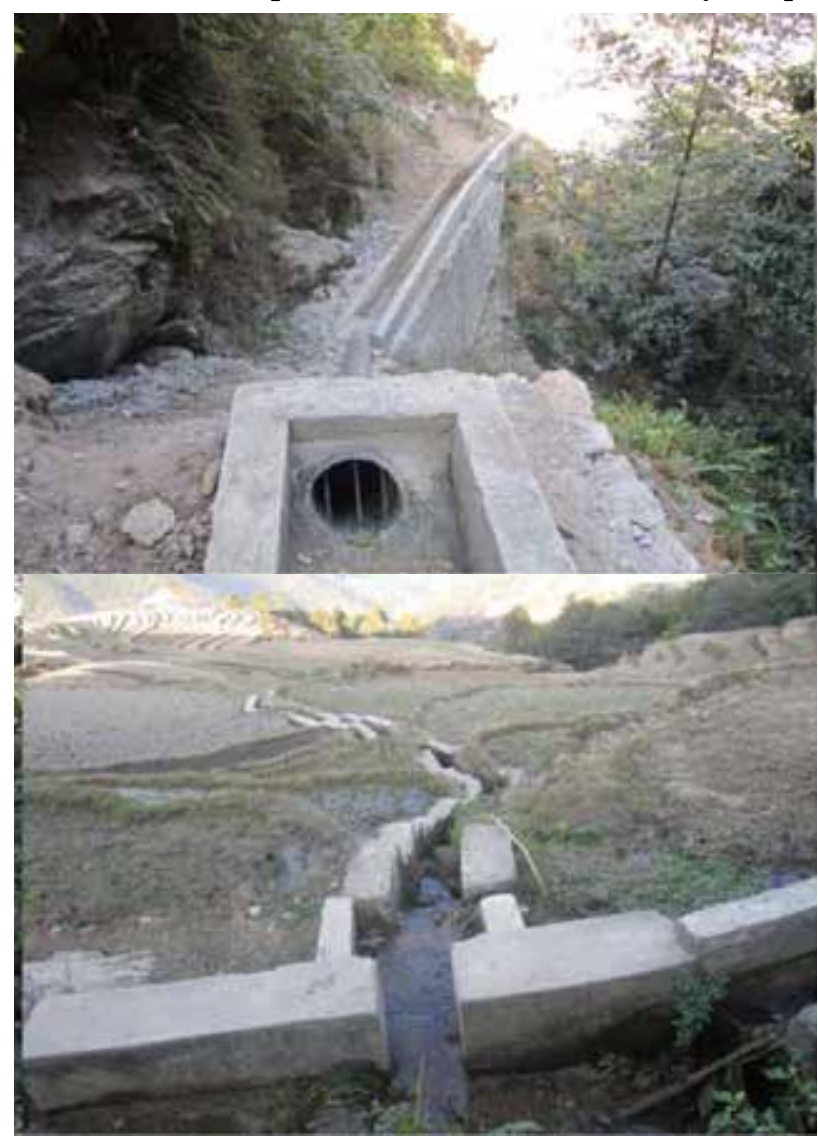

Photo 5: Comparision of pipe and masonry drops

used in irrigation system. Pipe drop is simple easy to construct and occupies less area of land.

\section{Better Control of Losses}

HDP is more durable over time and will minimize your losses due to seepage. RCC allows more seepage over time and the leaks are more difficult to detect and repair. Regarding discharge conveyance, HDP rates close to $100 \%$ compared to $70 \%$ for RCC. HDP is also superior for the fact that it is a closed system and does not lose water to evaporation.

\section{Erosion Control and Energy Dissipation}

In hill irrigation systems, sufficient head is available for canal alignment. If the canal is kept unlined, erosion will occurs in the canal bed and on the sides. A number of fall structures are also used in hill region canals. Cement based fall structures are quite heavy and costly. They can be simply replaced by use of HDP pipe which is lighter and more cost effective.

\section{Flexibility in the Selection of Alignment}

Canal alignment has to consider interruptions from buildings, forest, rocky slopes, and sliding zone. Since earthen canals and RCC allow only gravity flow, the alignment cannot be easily realigned and successive obstacles will gradually diminish the flow 
level in the canal. For this reason, this makes upper elevation command areas extremely challenging to establish. HDP pipe gets around all of these challenges

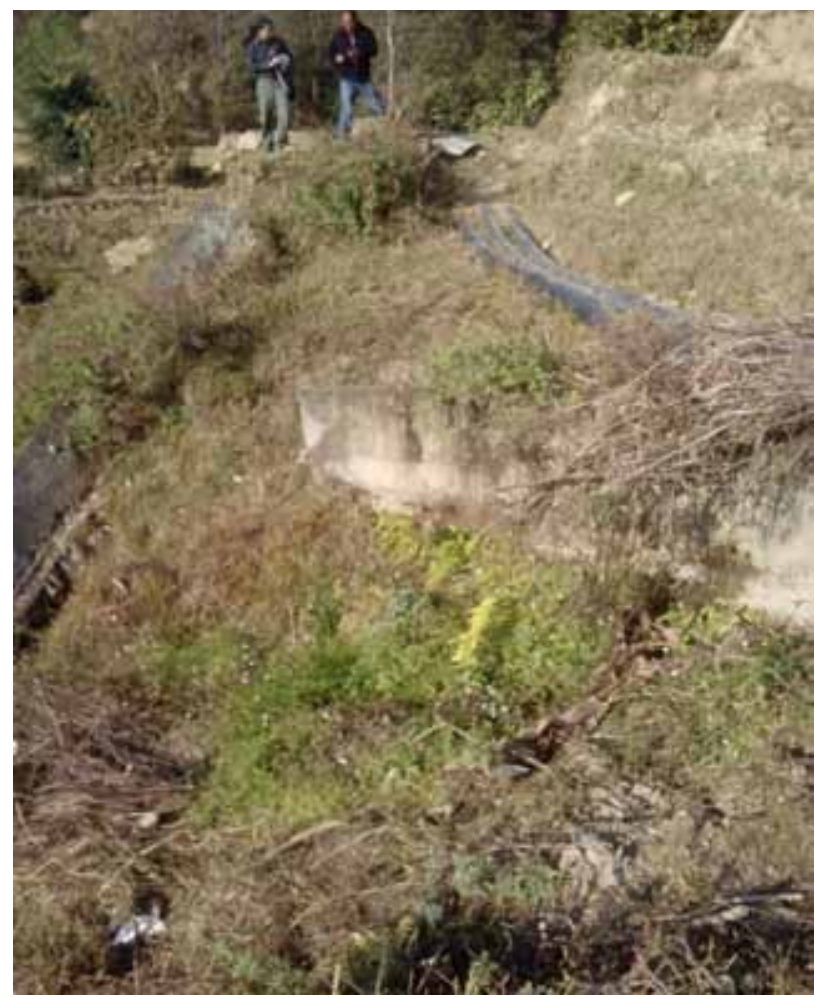

Photo 6: HDP Pipe used as emergency material at RCC canal breached section

because it allows pressure flow in its closed system, thus eliminating the need for relying on gravity or high elevation command areas.

\section{Economy of Land Use}

Generally, HDP is buried in the ground which maximizes land use in land scarce areas. Earthen canals cannot. Over the pipe buried, land cultivation and other general land use is possible.

\section{Exclusion of Leaves, Branches, Boulders and other Foreign Materials in the Conveyance System}

Open canals are often obstructed by debris: leaves, boulders, and other foreign materials. Because HDP pipes are closed, these systems will not become clogged. Also, because HDP is closed, the flow will not be impeded by the disposal of household garbage and other materials.

\section{Multipurpose Use of Irrigation Water}

While this paper has focused primarily on agricultural uses of canals, we should stress that HDP is also excellent for household uses of water. Water emerging from springs and streams are generally considered usable for domestic purposes. This gives HDP a multiplier effect on the overall efficiency of water use in remote settlements.

\section{Applicable to Lift Systems and Micro-Irrigation}

Pipes are unavoidable in lift systems and micro irrigation. Lift systems cannot be installed without pipes (Photo 7). A proper set of fittings provide better control to the pipe network (Photo 8). Similarly,

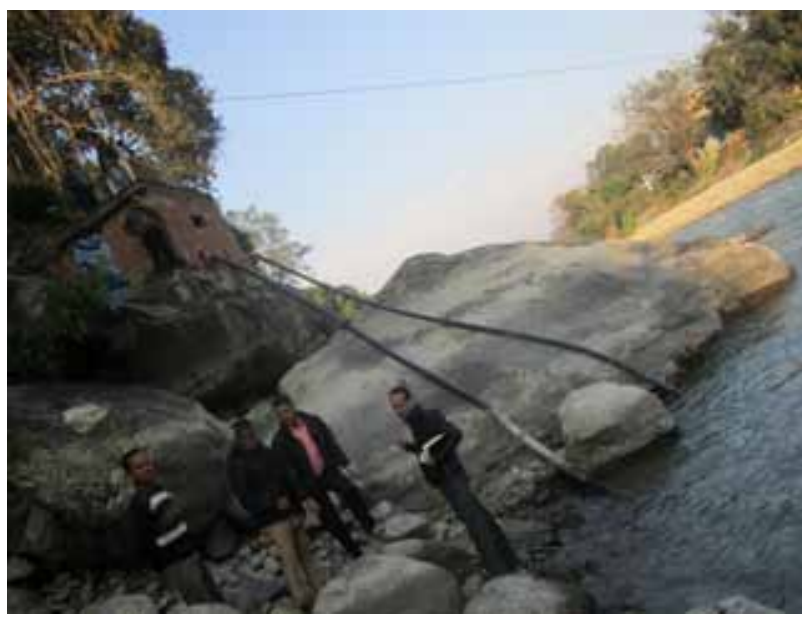

Photo 7: HDP pipe used for lift irrigation

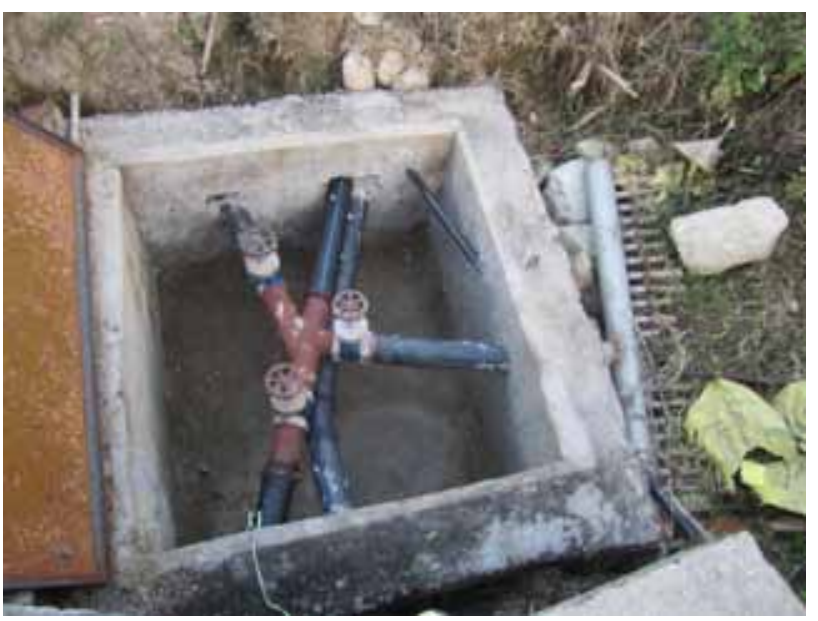

Photo 8: Better control of water

micro irrigation modes such as sprinkler and drip systems cannot be installed in surface flow systems. HDP pipe networks in such systems are economical and efficient, affordable to most individual farmers.

\section{Limitations}

HDP, however, is not superior in every way. It does have, like any technology, some limitations depending on the context.

\section{Availability of Pressure Head}

Head loss tends to be more pronounced in HDP closed systems compared to open channel. HDP can only be employed in areas where there is sufficient head available between the source and command area. This is why HDP is clearly superior in hilly areas where head is less of an issue, and less obviously favorable in terai where head becomes a concern.

\section{Discharge Limitation}

HDP pipe is limited in diameter, so it may not be suitable for conveying discharge above a certain level. HDP pipe can be obtained in multiple sizes, but each size up increases the cost of transportation and enhances the challenge of installation. 


\section{Clogging Problem}

Since HDP pipe is a closed conduit, it cannot be inspected when clogs occur, usually at the joints or in compound areas. This problem will exist in all areas, except the most hilly which have the highest velocity. In a worst case scenario, if the clogged location cannot be detected, the whole alignment might have to be abandoned or reconfigured.

\section{Vulnerability of Pipes in Exposed Condition}

HDP pipes are generally buried underground unless any difficulties warrant otherwise. This can be challenge when the pipe crosses over natural drains. If the crossing is long and pipe size is of big diameter, an expansion and contraction effect may occur at the joints. Similarly, exposed HDP pipes in rocky areas may be damaged by animals or people.

\section{Weak Bond with Cement Concrete}

RCC and masonry is still the best option for pressure break tanks and off-take chambers. HDP must be inserted through the walls of these tanks, but HDP is difficult to bond to cement and this could lead to leakage in the tank at the points of inlet and outlet.

\section{Unavailability of Control Valves and Fittings}

HDP pipe control valves and fittings are unavailable in bigger sizes in Nepal. This may cause problems in controlling flow from pipe lines and reservoirs.

\section{Conclusion}

In this paper, I explored the advantages of HDP linings for irrigation systems, particularly in rural or hilly regions of Nepal. Though HDP is superior is most aspects when compared to RCC linings, it is not a perfect technology and will require maintenance and supervision like any materials. In the end, the choice of lining type depends on a number of factors including site condition, cost, technical factors, physical and environmental considerations.

Krishna Prasad Rijal holds a master degree (Msc) in Water Resources Engineering from Tribnuvan University, Nepal. At present, he is working as a Senior Divisional Engineer in Central Regional Irrigation Directorate under the Department of Irrigation, Government of Nepal since 2006. He has 12 years of experience in Civil Engineering profession, especially in hydro sector. He is interested in research studies and training including project monitoring and evaluation, technical designs. He is the visiting faculty in National College of Engineering, Lalitpur, Nepal

Corresponding E-mail: krishnarijal@gmail.com 